\title{
Model-based remote sensing algorithms for particulate organic carbon (POC) in the Northeastern Gulf of Mexico
}

\author{
Young Baek Son ${ }^{1,2, *}$, Wilford D Gardner ${ }^{1}$, Alexey V Mishonov ${ }^{3}$ \\ and MARY JO RICHARDSON ${ }^{2}$ \\ ${ }^{1}$ Department of Fisheries, Nagasaki University, 1-14 Bunkyo, Nagasaki, Nagasaki 852-8521, Japan. \\ ${ }^{2}$ Department of Oceanography, Texas A\&M University, College Station, Texas 77843-3146, USA. \\ ${ }^{3}$ National Oceanographic Data Center, 1315 East West Highway, Silver Spring, MD 20910-3282, USA. \\ *e-mail: sonyb@nagasaki-u.ac.jp
}

\begin{abstract}
Hydrographic data, including particulate organic carbon (POC) from the Northeastern Gulf of Mexico (NEGOM) study, were combined with remotely-sensed SeaWiFS data to estimate POC concentration using principal component analysis (PCA). The spectral radiance was extracted at each NEGOM station, digitized, and averaged. The mean value and spurious trends were removed from each spectrum. De-trended data included six wavelengths at 58 stations. The correlation between the weighting factors of the first six eigenvectors and POC concentration were applied using multiple linear regression. PCA algorithms based on the first three, four, and five modes accounted for 90, 95, and 98\% of total variance and yielded significant correlations with POC with $R^{2}=0.89,0.92$, and 0.93 . These full waveband approaches provided robust estimates of POC in various water types.

Three different analyses (root mean square error, mean ratio and standard deviation) showed similar error estimates, and suggest that spectral variations in the modes defined by just the first four characteristic vectors are closely correlated with POC concentration, resulting in only negligible loss of spectral information from additional modes. The use of POC algorithms greatly increases the spatial and temporal resolution for interpreting POC cycling and can be extrapolated throughout and perhaps beyond the area of shipboard sampling.
\end{abstract}

\section{Introduction}

The Gulf of Mexico, a semi-enclosed basin with passages at the Yucatan Channel and the Florida Straits, is biologically productive in the continental shelf regions and has a physically complex regional and mesoscale circulation system (Vastano et al 1995; Walker 1996; Ohlmann and Niiler 2005). Several river systems on the surrounding land provide a large mass of fresh water to the shelf along with suspended sediments, organic and inorganic matter, and pollutants. Higher levels of materials in the Gulf of Mexico have a different spatial and temporal variability influenced by the seasonal and inter-annual variations of the local shelf and mesoscale circulations (Lohrenz et al 1990; Redalje et al 1994; Rabalais et al 1996; Walker 1996). These conditions can sometimes cause negative impacts resulting from high productivity and subsequent carbon export, which may contribute to the formation of 'dead zones' of hypoxia such as along the Gulf Coast. The Northeastern Gulf of Mexico (NEGOM), Louisiana-Texas Shelf Physical Oceanography Program (LATEX), and hypoxia studies have provided useful information for characterizing the oceanic environment of the northern Gulf of Mexico region (Redalje et al 1994; Cho et al 1998; DiMarco and Reid 1998). These studies have

Keywords. Particulate organic carbon; principal component analysis; remote sensing algorithm. 
greatly expanded our knowledge on many parameters of the carbon pool as well as hydrography. However, carbon measurements have been made in a limited number of programs.

Particulate organic carbon (POC) plays a key role in the transport of carbon in the ocean through the biological pump. While $\mathrm{CO}_{2}$ and dissolved organic carbon (DOC) move with the water, POC can settle through the water column, across isopycnals, scavenging or aggregating other particles and transporting carbon and associated elements to deeper waters. Thus POC is a key component in the ocean's role in sequestering and isolating carbon from the atmosphere. Because POC is produced/cycled on day-to-week time scales, a synoptic picture of POC changes can only be obtained by employing remote sensing techniques. To investigate more components of the carbon cycle, empirical approaches have been developed recently based on the optical closure relationships using single or multiple spectral wavelengths and provide a reasonable assessment of POC distribution on regional to global scales (Stramski et al 1999, 2008; Loisel et al 2001; Mishonov et al 2003; Stramska and Stramski 2005; Gardner et al 2006; Son 2006; Son et al 2009). Several empirical approaches have been used for estimating chlorophyll concentration in ocean color studies, as well as using model-based approaches based on orthogonal vector analyses, using remote sensing data (Mueller 1976; Gower et al 1984; Fischer et al 1986; Sathyendranath et al 1989; Neumann et al 1995) but the latter approaches have not been studied sufficiently for POC concentration.

The principal component analysis (PCA), one of the model-based approaches to estimate water constituents, is generally used to produce a reduced variance for the analysis of information in multidimensional datasets. PCA is used to analyze information from empirical or modeled datasets and to separate the signal from noise (Mueller 1976; Neumann et al 1995; IOCCG 2000). In ocean color studies a characteristic vector analysis method using multiple wavelengths has been introduced to determine the relationship between chlorophyll concentrations and spectral wavelengths, and enhance the potential discrimination and reconstruction accuracy of constituents present (Mueller 1976; Gower et al 1984; Fischer et al 1986; Sathyendranath et al 1989; Neumann et al 1995; IOCCG 2000). In this study, the main idea is to develop accurate and efficient POC algorithms using a model-based approach employing multiple wavelengths and in situ measurements. This method can be optimized to take into account regional or seasonal variations by applying regional optical models to derive the weighting coefficients for the estimator. It is important for quantifying the time-varying evolution of POC in surface waters to monitor, and eventually model, the impact of climate change on surface water biomass and productivity (Son 2006).

\section{Data and methods}

\subsection{In situ shipboard data}

In order to understand the spatial and temporal physical processes in the northern Gulf of Mexico, the Northeastern Gulf of Mexico (NEGOM) project conducted nine cruises from November 1997 to August 2000 along the same eleven track lines. Each seasonal cruise was completed along lines normal to the coastline between mid-Florida and the Mississippi River, starting from about $20 \mathrm{~m}$ water depth on the shelf and moving out to the $1000 \mathrm{~m}$ isobath (figure 1). This area spans a wide range of particle concentrations and types, from turbid river runoff to clear and open-ocean waters.

POC samples were collected from rosette water bottles at about half of the stations ( $\sim 60$ sampling points). Prior to each cruise, 25-mm diameter GF-75 (approximately $0.7 \mu \mathrm{m}$ pore size) glassfiber filters were combusted in a thermolyne type 1300 furnace along with aluminum foil squares to oxidize any organic traces on the filters and foil (Gordon 1969; Sharp 1974; JGOFS 1996). During each cruise, water samples $(1 \sim 3$ liters $)$ including all organic particles were filtered to determine concentrations of POC at each of the $\sim 60$ stations. The filters were then wrapped in aluminum foil and placed in a drying oven under low heat, approximately $30^{\circ} \mathrm{C}$, for $3-4$ hours (Bernal 2001). After each cruise the filters were acidified to remove the carbonates and combusted, converting the organic carbon to $\mathrm{CO}_{2}$, which was then measured by thermal conductivity (JGOFS 1996). Blank (unused and pre-combusted filters) corrections were applied and results were given in concentration of $\mathrm{mg} / \mathrm{m}^{3}$.

\subsection{Satellite data}

Daily SeaWiFS satellite images (Level 1A) covering the Gulf of Mexico were obtained from the NASA Goddard Space Flight Center DAAC archives (http://oceancolor.gsfc.nasa.gov/). L1A images were processed to Level 2 using the SeaWiFS Data Analysis System (SeaDAS) (Baith et al 2001; McClain et al 2004) software. The spectral normalized water-leaving radiance $\left(L_{w n}\right)$ were derived from the SeaWiFS Level 2 (geolocated, geophysical values, L2) data using the SeaDAS standard correction algorithm for all eight 


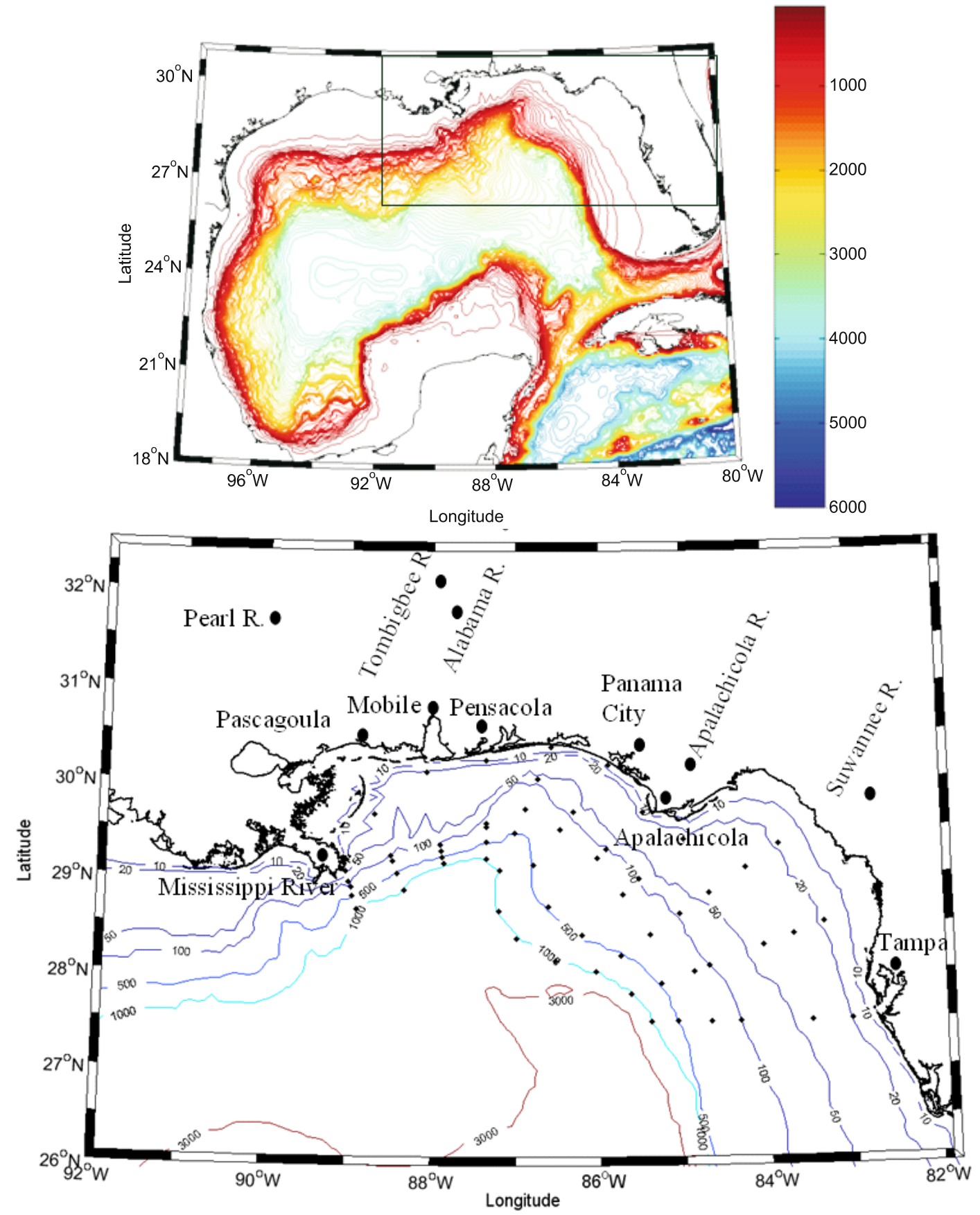

Figure 1. Bathymetry and sampling stations in the Northeastern Gulf of Mexico (NEGOM) occupied during 9 cruises from November 1997 to August 2000 (11 sampling transects and 60 POC sampling stations).

spectral channels. The derived six visible wavelengths $(412,443,490,510,555$, and $670 \mathrm{~nm})$ data were used to develop an algorithm to estimate POC.

\subsection{Model-based approach}

A match-up dataset between in situ measurements and satellite data synchronously obtained from the same cruise time was generated. The empirical match-up analysis adopted the NASA Ocean
Biology Processing Group's (OBPG) approach (Bailey et al 2000, 2006). In our study, we used $3 \times 3$ pixel grid (i.e., $>4$ valid pixels) instead of a $5 \times 5$ pixel grid. The 58 POC sub-samples, which totaled about $11 \%$ of the total 526 POC samples, were matched with the SeaWiFS spectral data within \pm 3 hours of POC sampling and within \pm 3 hours of local noon.

In this study, PCA was used to determine the information from empirical datasets, to transform the data in a manner suitable for analysis, and 
to separate a useful signal from noise in the data. This correlated dataset was used to determine the spectral dimensionality of the data, and the weighting of each spectral channel required to estimate the variables of interest (Gower et al 1984; Sathyendranath et al 1989; IOCCG 2000).

We first removed the calculated mean value $\mu(\lambda)$ from each normalized water leaving radiance $(\lambda)$. We also computed and removed any linear trend existing in the record deemed to be spurious. The resulting de-meaned series of $D(\lambda)$ are termed standardized as:

$$
D_{n}(\lambda)=\sum_{i=1}^{n} \sum_{j=1}^{m}\left[L_{i}\left(\lambda_{j}\right)-\mu\left(\lambda_{j}\right)\right]
$$

where $L$ is the spectral remote sensing dataset of original $N \times M$ matrix, $i$ is the observation number and $j$ is the measurement at the given spectral wavelength.

The computationally efficient singular value decomposition (SVD) of a matrix is applied to calculate eigenvectors and eigenvalues. SVD is based on the concept that any rectangular $N \times M$ matrix $D_{n}(\lambda)$ can be written as the product of three matrices: an $N \times N$ matrix $U$, a $N \times M$ diagonal matrix $\Gamma$ with positive or zero elements, and the transposition $\left(V^{\dagger}\right)$ of the $M \times M$ matrix $V$.

$$
D_{n}(\lambda)=U \times \Gamma \times V^{\dagger} .
$$

Matrix $\Gamma$ is a rectangular $N \times M$ matrix with zero elements outside the diagonal and positive or zero elements on the diagonal. The scalars on the diagonal, $\gamma_{k}$, are called the singular values and are typically placed in decreasing order of magnitude. Again, there is a maximum of $k \leq \min (N, M)$ nonzero singular values, which defines the maximum number of PCA modes we can determine, so that the effective dimension of matrix $\Gamma$ is $k \times k$.

An original observation vector, $L$, may be transformed into its characteristic system representation through the $k$ equations.

$$
\begin{aligned}
\mathrm{PC}_{i} & =\sum_{j=1}^{n} e_{i j} \times D_{j} ; \\
i & =1,2, \ldots, k \text { and } j=1,2, \ldots, N,
\end{aligned}
$$

where $\mathrm{PC}_{i}$ is called the $i$ th principal component of $D_{i}$ and characteristic vector $e_{i j}$ is the $i$ th characteristic vector. Thus, we effect the transformation

$$
\left(D_{1}, D_{2}, \ldots, D_{N}\right) \rightarrow\left(\mathrm{PC}_{1}, \mathrm{PC}_{2}, \ldots, \mathrm{PC}_{k}\right)
$$

where $k$ is less than or equal to $N$ to retain the desired proportion of sample variance.

\section{Results and discussions}

\subsection{A model-based approach (principal component analysis)}

The spectral normalized water-leaving radiances at six wavelengths for 58 stations were analyzed using PCA analysis to obtain the eigenvalues and eigenvectors of the dimensionally reduced data. The principal components (PCs) of the first six characteristic vectors were calculated. The correlation between these PCs and POC concentrations was determined using multiple linear regression and added weighting factors. This approach reduced the data to a small number of orthogonal vectors and the corresponding weight factors for each sample. The reduced dataset simplifies the task of information extraction and interpretation (Mueller 1976; Gower et al 1984; Sathyendranath et al 1989).

In the first approach, we compared discrete POC concentration with averaged radiance data from each NEGOM cruise. Figure 2(a) graphically shows the total variance calculated by PCA. The first and second modes (54 and $27 \%$ ) were clearly dominant, followed by a steep drop in variance of the third and fourth modes, which accounted for 10 and $4 \%$ of the total variance respectively. The first three, four, and five modes accounted for 90, 94, and 98\% of total variance.

In figure 2(b), the peak in the mean spectral radiance occurred at the shorter wavelengths and rapidly dropped off in the green and red wavelengths. In examining individual eigenvectors, the first eigenvector showed a small maximum at $555 \mathrm{~nm}$. The maximum in the second eigenvector occurred at the shortest wavelength measured $412 \mathrm{~nm}$, and the third eigenvector maximum was at $490 \mathrm{~nm}$ (figure 2c). The other three eigenvectors had double maxima but lower eigenvalues $(<4 \%$ of total variance, figure $2 \mathrm{~d}$ ).

The first eigenvector shows high values at longer wavelengths, perhaps due to increased scattering from elevated concentrations of nonliving and living organic particles. The maximum of the second vector is shifted to shorter wavelengths, 

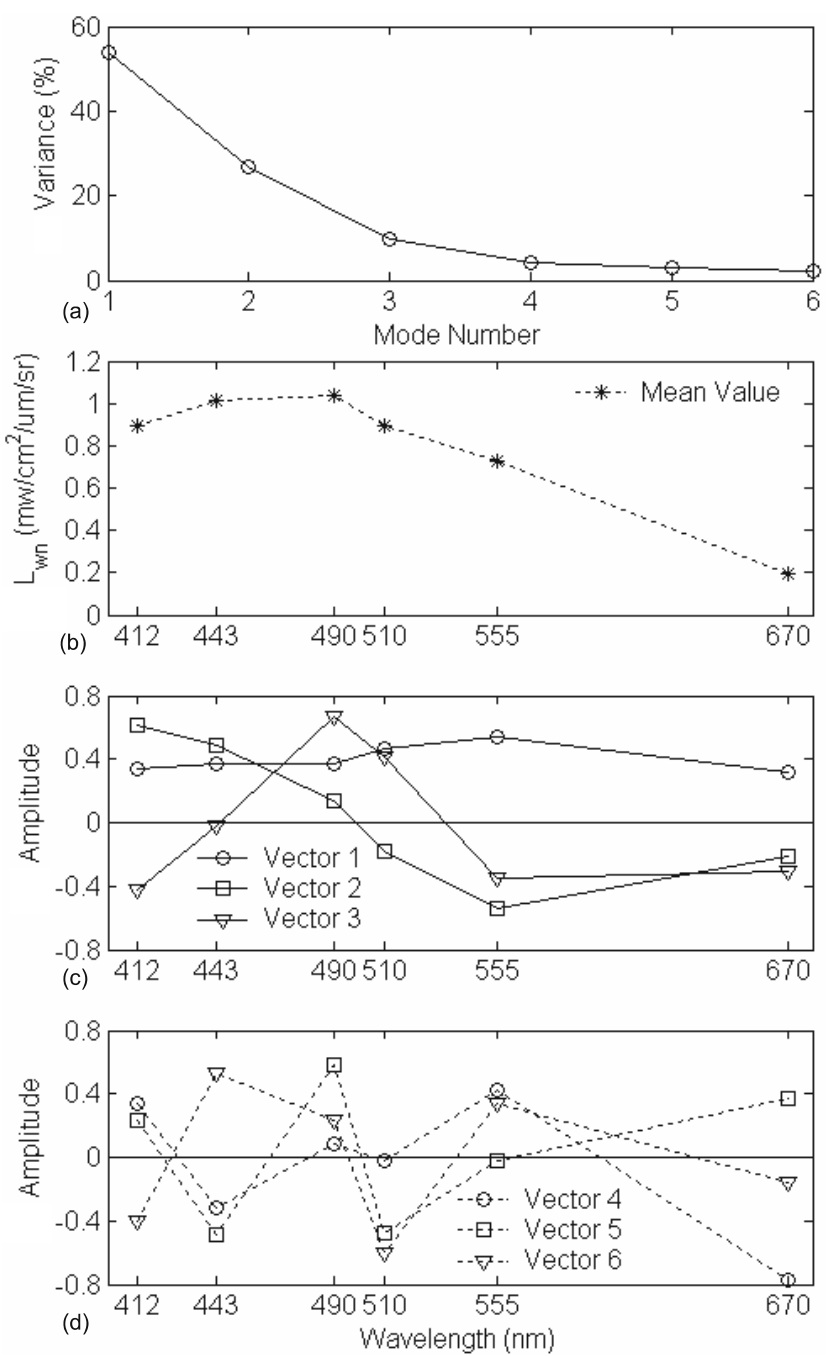

Figure 2. PCA analysis using 58 samples and six wavelengths: (a) Total variance versus PCA mode number, (b) mean spectral radiance versus wavelength, and $(\mathbf{c}, \mathbf{d})$ the first six eigenvectors derived from NEGOM data. The first eigenvector showed that the maximum occurred at $555 \mathrm{~nm}$, the second eigenvector shows maximum at $412 \mathrm{~nm}$, and the third at $490 \mathrm{~nm}$. Eigenvectors $4-6$ show double maxima.

violet-blue wavelengths, which is the characteristic of increasing radiance due to low absorption. The third vector appears to be a combination of moderate concentrations of nonliving and living organic particles at $490 \mathrm{~nm}$ (figure 2c). The fourth and fifth vectors show lower radiance peaks at $670 \mathrm{~nm}$ and the sixth vector has a high value at $670 \mathrm{~nm}$. The shapes of vectors reveal that spectral response depends on absorption/scattering of nonliving and living organic particles (Gower et al 1984, figures $2 \mathrm{c}$ and $2 \mathrm{~d}$ ).

We can observe the patterns of characteristic eigenvectors from the spectral response curve (Son 2006; Son et al 2009). When the POC concentration in the surface water increased, the radiance peak shifted from the shorter wavelengths
(412 and $443 \mathrm{~nm}$, violet-blue band) to longer wavelengths ( $555 \mathrm{~nm}$, green band). Radiance at $510 \mathrm{~nm}$ remained at a relatively constant value over a wide range of POC concentrations $(<20$ to $\left.>550 \mathrm{mg} / \mathrm{m}^{3}\right)$. One would expect that at lower POC concentration, the spectral curve maximum would shift to shorter wavelengths, since blue water-leaving radiance should increase (relative to longer wavelengths where light does not penetrate as deeply). When POC concentration increases, the radiance peak shifts towards longer wavelengths as radiance from particles dominates the signal.

However, a fixed number of spectral radiances in model-based approaches does not yield an equal number of independent constituents affecting the radiance because of the similarity in the spectral response generated by different oceanic constituents (Fischer 1985), i.e., the spectral response of different constituents in the water is not unique. Therefore, only a small number of spectral measurements yield independent information about water constituents of interest. The degree of interdependence between radiances measured at different wavelengths can be determined with an eigenvalue analysis (Twomey 1977). The orthogonality of the radiance signals of the individual components will determine our ability to recover these components from the total radiance spectrum.

A least-squares fit of the principal component (PC) values to POC concentrations using the multiple-linear regression method showed that POC estimates $\left(\mathrm{mg} / \mathrm{m}^{3}\right)$ were related to each principal component of the SeaWiFS visible wavelengths by the equation:

$$
\mathrm{POC}=10^{\left(-0.1 \times \mathrm{PC}_{1}+0.66 \times \mathrm{PC}_{2}+0.474 \times \mathrm{PC}_{3}+2.054\right)},
$$

where $\mathrm{PC}_{1,2,3}$ are the principal components of the first three modes using surface POC and averaged radiance data from each NEGOM cruise.

Equation (4) demonstrates that weighting vectors 2 and 3 contributed roughly equally to describing the effects of POC concentration but vector 1 anti-correlated with POC (negative exponent for $\left.\mathrm{PC}_{1}\right)$. Figure $3(\mathrm{a})$ and table 1 show the scatter plot between in situ surface POC measurements and POC estimates using equation (4). This multiple regression was well correlated with lower POC concentration but scattered at higher POC concentration $\left(R^{2}=0.89, N=58\right)$. To determine a quantitative algorithm evaluation, Son et al (2009) provided a useful method to distinguish between samples dominated by organic and inorganic components based organic percent. Through 

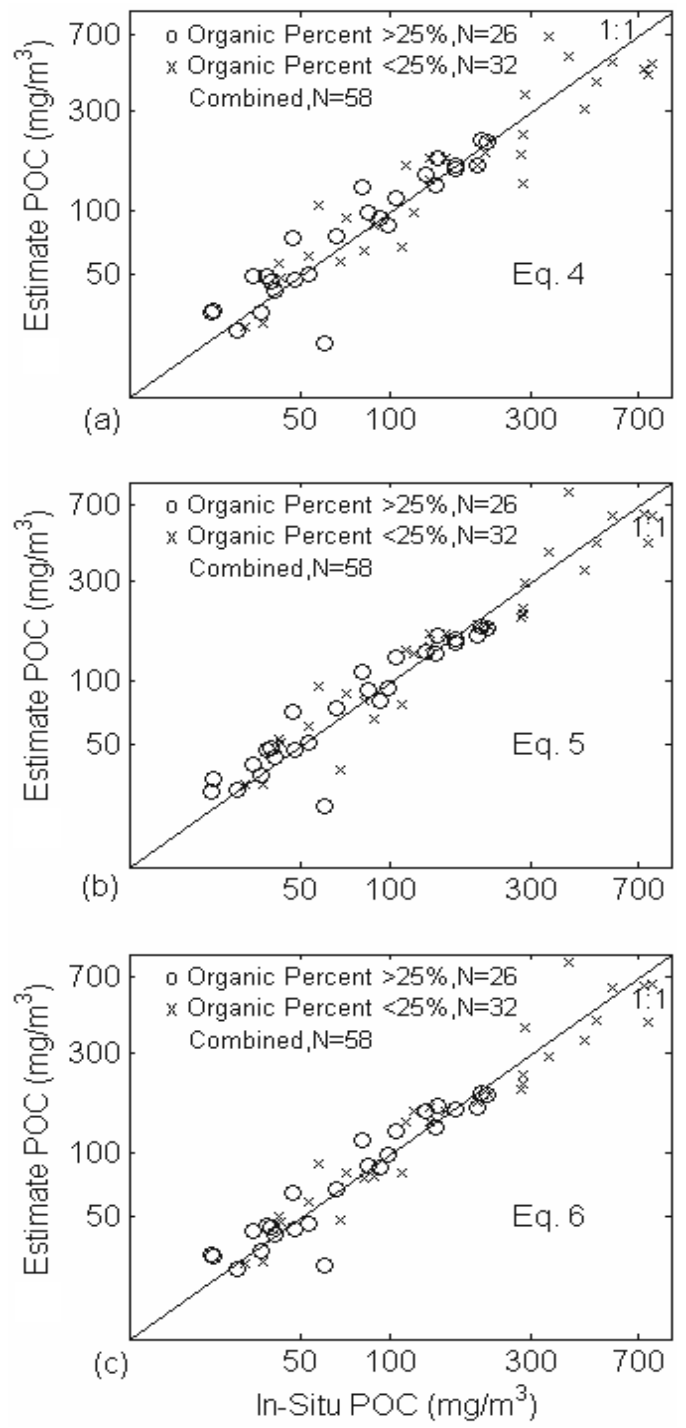

Figure 3. Comparisons between in situ POC and estimated POC using three different algorithms based on multiple linear regression and weighted PCA vectors. Data are delineated by percent organic carbon $>25 \%$ and $<25 \%$. The lines are 1:1 slopes. All correlation statistics are in table 1.

empirical analysis they found that the $25 \%$ value best correlated POC/PM and beam attenuation coefficient due to particles at $660 \mathrm{~nm}, c_{p}$. This assessment demonstrated that POC was better related to $c_{p}$ when organic matter dominated the total mass of particles, as one would expect (organic matter $\sim 2 \times$ POC). We applied this relationship between the measured and estimated POC to our study. Figure 3 and table 1 provide correlation plots and statistical data between discrete POC measurements and POC estimates obtained with three different algorithms (equations 4-6) using samples where organic percent $>25 \%,<25 \%$, and combined POC samples. The root mean square error (RMSE), mean ratio values between the in situ POC and POC estimates, as well as the corresponding standard deviation were computed and tabulated in table 1 . The results of RMSE, mean ratio, and standard deviation where POC $>25 \%,<25 \%$, and combined POC samples were not significantly different; the regression slightly overestimated when organic percent $>25 \%$ and underestimated when organic percent $<25 \%$ (table 1).

Equation (5) reveals that weighting vectors 2, 3, and 4 contributed similarly to describe the effects of POC concentration but vector 1 anti-correlated with POC. Figure 3(b) shows the scatter plot between in situ surface POC measurements and POC estimates obtained with equation (5). The correlation revealed a good relationship between POC measurements and weighted spectral data $\left(R^{2}=0.92, N=58\right)$. The results of error analysis where $>25 \%,<25 \%$, and combined POC samples provided a closer correlation between in situ and estimated POC than the previous approach (equation 4).

$$
\mathrm{POC}=10 \quad \begin{gathered}
\left(-0.1 \times \mathrm{PC}_{1}+0.66 \times \mathrm{PC}_{2}+0.474\right. \\
\left.\times \mathrm{PC}_{3}+0.84 \times \mathrm{PC}_{4}+2.054\right),
\end{gathered}
$$

where $\mathrm{PC}_{1,2,3,4}$ are the principal components of the first four modes.

Equation (6) demonstrates that weighting vectors 2,3 , and 4 contributed similarly to describing the effects of POC concentration but vectors 1 and 5 anti-correlated with POC (negative exponents). Figure 3(c) and table 1 show the scatter plot and statistics between in situ surface POC measurements and POC estimates using equation (6). This multiple regression reveals a significant correlation between POC measurements and weighted spectral data with $R^{2}=0.93(N=58)$. Although this approach using equation (3) provided reasonable estimates of POC concentrations regardless of whether organic percent was $>25 \%,<25 \%$, or combined, the RMS error was not significantly different than with equation (5).

$$
\mathrm{POC}=10 \begin{gathered}
\left(-0.1 \times \mathrm{PC}_{1}+0.66 \times \mathrm{PC}_{2}+0.474 \times \mathrm{PC}_{3}\right. \\
\left.+0.84 \times \mathrm{PC}_{4}-0.693 \times \mathrm{PC}_{5}+2.054\right)
\end{gathered}
$$

where $\mathrm{PC}_{1,2,3,4,5}$ are the principal components of the first five modes.

In figure 3 and table 1 , the first three, four, and five vectors demonstrated different weighting factors with varying POC concentrations showing similar effects of POC concentrations. Although the first three vectors accounted for about $90 \%$ of the total variance, the POC concentrations 
Table 1. Regression (type II) of in-situ POC versus estimated POC from algorithms: RMSE = $\sqrt{\sum\left(\log 10\left(\text { estimate }_{-} P O C\right)-\log 10(\text { in }- \text { situ } P O C)\right)^{2} /(N-1)}$, mean ratio $=1 / N \sum\left(\log 10\left(\right.\right.$ estimate $\left.e_{-} P O C\right) /$ $\log 10($ in - situ $P O C))$, the corresponding standard deviations, bias are calculated with $P O C>25 \%,<25 \%$, and combined POC samples.

\begin{tabular}{|c|c|c|c|c|c|c|c|}
\hline Organic percent & Slope & Intercept & $R^{2}$ & RMSE & Mean ratio & $\begin{array}{l}\text { Standard } \\
\text { deviation }\end{array}$ & $N$ \\
\hline \multicolumn{8}{|l|}{ Equation (4) } \\
\hline$>25 \%$ POC & 0.924 & 0.166 & 0.852 & 0.118 & 1.016 & 0.068 & 26 \\
\hline$<25 \% \mathrm{POC}$ & 0.880 & 0.244 & 0.877 & 0.144 & 0.994 & 0.066 & 32 \\
\hline Combined & 0.889 & 0.228 & 0.889 & 0.133 & 1.004 & 0.067 & 58 \\
\hline \multicolumn{8}{|l|}{ Equation (5) } \\
\hline$>25 \%$ POC & 0.889 & 0.220 & 0.880 & 0.103 & 1.010 & 0.059 & 26 \\
\hline$<25 \%$ POC & 0.932 & 0.140 & 0.916 & 0.119 & 0.997 & 0.056 & 32 \\
\hline Combined & 0.922 & 0.161 & 0.922 & 0.112 & 1.003 & 0.058 & 58 \\
\hline \multicolumn{8}{|l|}{ Equation (6) } \\
\hline$>25 \% \mathrm{POC}$ & 0.930 & 0.142 & 0.905 & 0.092 & 1.009 & 0.053 & 26 \\
\hline$<25 \%$ POC & 0.934 & 0.136 & 0.925 & 0.112 & 0.997 & 0.050 & 32 \\
\hline Combined & 0.933 & 0.138 & 0.933 & 0.103 & 1.002 & 0.052 & 58 \\
\hline
\end{tabular}

estimated using the first three vectors and weighting factors had a slightly higher error (table 1). Adding the fourth or fifth vectors and weighting factors provided a better correlation over a wide range of surface POC concentrations. These higher vectors appear to provide more systematic information about high POC concentrations which are affected by strong absorption and scattering radiances. However, each vector provided reasonable POC estimates for turbid waters. One, or a combination of the weighted eigenvalues reduced the noise levels from an optically complex environment. Although this linear approach does not accurately describe the physical relationship between principal components of the spectral radiance and POC concentration, the results of PCA demonstrate that using the first four vectors rather than all six lost virtually no information about the original constituents and provided a better correlation than using a single-wavelength ratio (Son 2006; Son et al 2009). In a previous study (Son 2006; Son et al 2009), the empirical POC approach used all wavelengths from blue to green to reduce the scatter of radiance signal. It was demonstrated that to obtain the best POC estimates in complex waters requires complex algorithms using 4-6 wavelengths rather than a single wavelength or the simple blue-togreen ratios typically used for open ocean waters. The empirical and model-based approaches employ full spectral radiance information and are well correlated with a broad range of POC concentrations. Still, further studies are necessary to establish a databank of spectral signatures of different water constituents using multispectral, multivariate data (Gower et al 1984; Sathyendranath et al 1989; IOCCG 2000).
Figure 4 is the reconstruction of estimated POC using the PCA algorithm (equation 4) and ocean color data collected by SeaWiFS Level 1A (1.1 km resolution). The PCA approach employed full spectral radiance information and was well correlated at lower and higher POC concentration. The most notable difference between maps constructed strictly from field data and POC maps from PCA analysis applied to SeaWiFS data, is the more detailed spatial pattern of POC, especially in coastal areas which were excluded during shipboard sampling. Cruises N1/N4/N7 were completed during fall, N2/N5/N8 - during spring, and N3/N6/N9 - during summer. The range of PCA-POC concentrations within the area circumscribed by the bottle samples was $17-889 \mathrm{mg} / \mathrm{m}^{3}$. The geometric mean based on the PCA algorithm was $121 \pm 39 \mathrm{mg} / \mathrm{m}^{3}$ for the fall seasons, $124 \pm 50 \mathrm{mg} / \mathrm{m}^{3}$ for the spring seasons, and $200 \pm$ $41 \mathrm{mg} / \mathrm{m}^{3}$ for the summer seasons. During the fall and early spring, elevated POC concentrations were confined to the inner shelf. During the late spring and summer, elevated POC concentrations extended out to the outer shelf and the upper slope. During those summer cruises the Loop Current and eddies, drew water from the Mississippi area out beyond the shelf into the open Gulf of Mexico. However, the close fit between POC estimates for PCA and measured POC suggests that spectral variations in the modes defined by the first four characteristic vectors are more closely related to POC concentration than with other optically important properties of sea water such as phytoplankton, suspended inorganic matter or CDOM. Thus, this algorithm should be valid in waters with 


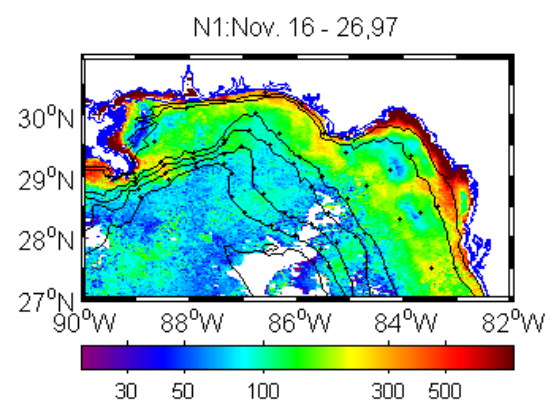

N4:Nov. 13 - 24,98

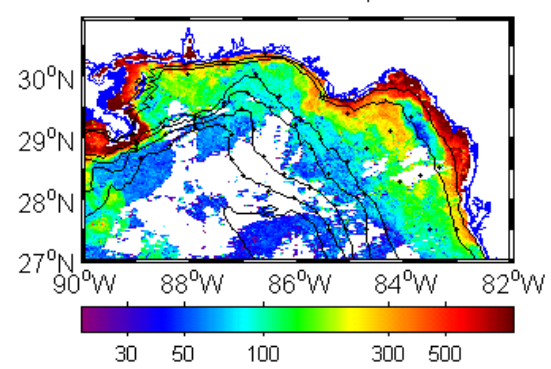

N7:Nov. $13-22,99$

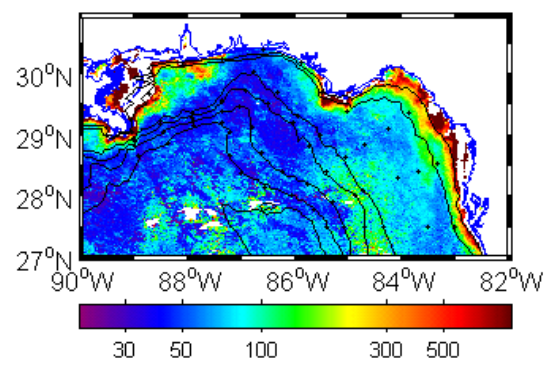

N2:May. $05-16,98$

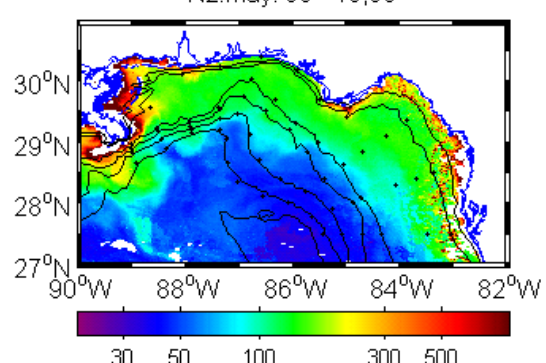

N5:May. 15 - 28,99

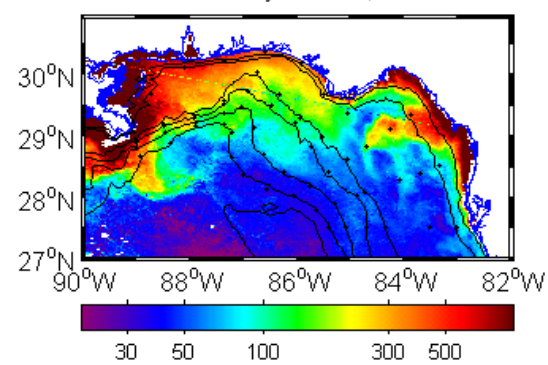

N8:Apr. 15 - 26,00

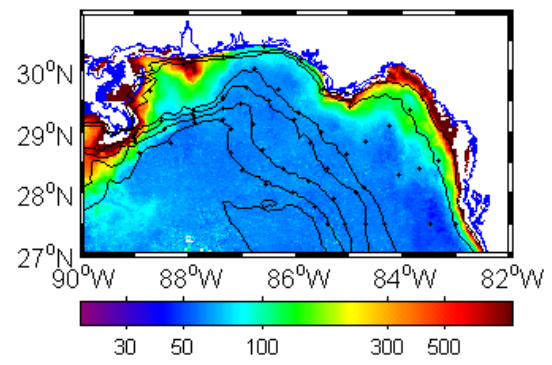

N3:Jul.26-Aug.6.98

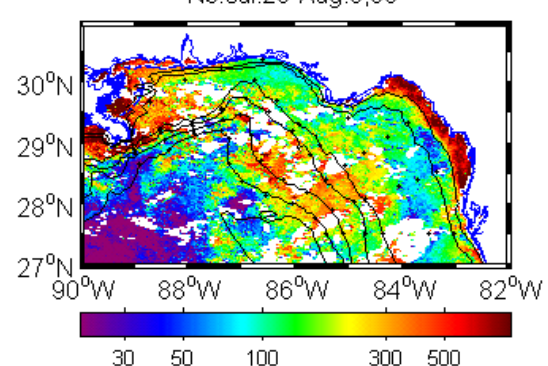

N6:Aug. $16-28,99$

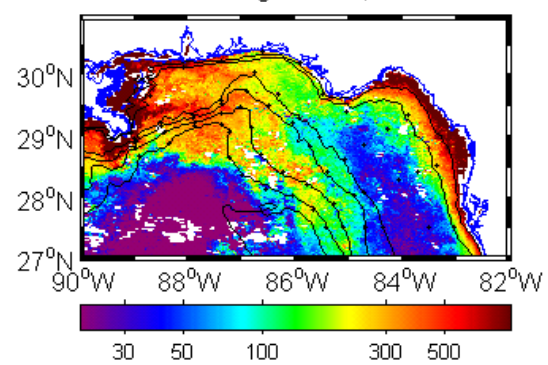

N9:Jul.28-Aug.8,00

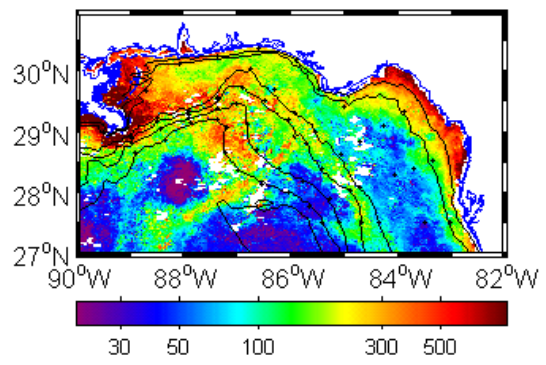

Figure 4. Estimated POC concentration $\left(\mathrm{mg} / \mathrm{m}^{3}\right)$ in the Northeastern Gulf of Mexico. Each map is compiled using PCA equation (5). POC estimates are well correlated with in situ data at both low and high POC concentrations.

both high and low \%POC (i.e., coastal and openocean waters). Since the accuracy of the PCA was similar in high and low \% POC waters, it opens the question whether this algorithm could be applied to larger regions or even globally. We tested the PCA using a few samples from other oceans with promising results, but more data and testing are required.

Son et al (2009) presented more detailed information about the difference between the bottle measurements and estimated POC. A later paper will use multivariate analysis to examine the distribution of POC and many other environmental factors (wind, temperature, chlorophyll, river runoff, etc.) that influence those distributions based on the work of Son (2006).

\section{Conclusions}

Using large datasets that include in situ measurements and ocean color products, the classical approach for estimating POC with high spatial resolution over wide areas is to develop empirical or model-based algorithms. From our analysis of the spectral response curve, we found that the peak spectral radiance was significantly dependent on POC concentration (Gower et al 1984; Sathyendranath et al 1989). Three different model-based PCA approaches using the spectral dependence were developed for POC estimates from normalized water-leaving radiances at six wavelengths. The characteristic eigenvalues and eigenvectors were derived from the reduced dimension of the spectral radiances. Nearly the entire variability of spectral radiances for POC estimates could be explained by the first three, four, or five modes (90, 95, and 98\% of total variances). The first vector yielded information about higher POC concentrations. The second vector yielded information about lower POC concentrations. The third vector provided information about moderate POC concentrations. Other vectors did not yield further information about POC concentration, most likely because of the optically complex conditions due to one or more influences of scattering 
and absorption conditions by phytoplankton, suspended inorganic matter or CDOM.

Although the results of PCA algorithms tested by three different approaches reveal a significant relationship between in situ measurements and estimated POC, the POC algorithm which employed the first four modes showed that the derived relations were most sensitive when using all SeaWiFS wavelengths over the entire range of in situ POC concentrations. These algorithms are promising for mapping POC concentration regionally based on remote sensing data as it clearly reproduces the spatial distribution and seasonal cycles in the Gulf of Mexico. This approach for developing algorithms appears useful for estimating and monitoring POC concentrations at least on regional scales, and should be tested on even broader spatial scales.

\section{Acknowledgements}

We thank Christina Bernal for collecting the shipboard data for this paper as part of her thesis work during the Minerals Management Service's Northeastern Gulf of Mexico Physical Oceanography Program (NEGOM). The help from scientists and technicians who participated in NEGOM is also appreciated. Support for YBS was graciously provided by Texas A\&M University. NSF grants OCE-9986762 and OCE-0137171 provided partial support. The NASA scientists who continually generate excellent SeaWiFS data are gratefully acknowledged.

\section{References}

Bailey S W, McClain C R, Werdell P J and Schieber B D 2000 Normalized water-leaving radiance and chlorophyll a match-up analyses; NASA Technical Memorandum, vol. 206892, Greenbelt, USA.

Bailey S W and Werdell P J 2006 A multi-sensor approach for the on-orbit validation of ocean color satellite data products; Remote Sens. Environ. 102 12-23.

Baith K, Lindsay R, Fu G and McClain C R 2001 Data analysis system developed for ocean color satellite sensors; EOS $\mathbf{8 2} 202$.

Bernal C E 2001 Spatial and Temporal Distributions of Particulate Matter and Particulate Organic Carbon, Northeast Gulf of Mexico; M.S. Thesis, Texas A\&M University, USA.

Cho K W, Reid R O and Nowlin W D 1998 Objectively mapped stream function fields on the Texas-Louisiana shelf based on 32 months of moored current meter data; J. Geophys. Res. 103 10377-10390.

DiMarco S F and Reid R O 1998 Characterization of the principal tidal current constituents on the TexasLouisiana shelf; J. Geophys. Res. 103 3093-3109.

Fischer J 1985 On the information content of multispectral radiance measurements over an ocean; Int. J. Remote Sens. 6 773-786.
Fischer J, Doerffer R and Grassl H 1986 Factor analysis of multispectal radiance over coastal and open ocean water based on radiative transfer calculations; Appl. Opt. $\mathbf{2 5}$ 448-456.

Gardner W D, Mishonov A V and Richardson M J 2006 Global POC concentrations from in-situ and satellite data; Deep-Sea Res. II 53 718-740.

Gordon Jr D C 1969 Examination of methods of particulate organic carbon analysis; Deep-Sea Res. 16 661-665.

Gower J F R, Lin S and Borstad G A 1984 The information content optical spectral ranges for remote chlorophyll estimation in coastal waters; Int. J. Remote Sens. $\mathbf{5}$ 349-364.

IOCCG 2000 Remote sensing of ocean colour in coastal and other optically-complex waters; In: Report of the International Ocean-Color Coordination Group, No. 3, (ed.) Sathyendranath S, Dartmouth, 140 pp.

JGOFS 1996 Protocols for the Joint Global Ocean Flux Study (JGOFS) core measurements, Report \#19, Intergovernmental Oceanographic Commission, Bergen, Norway, 170 pp.

Lohrenz S E, Dagg M J and Whitledge T E 1990 Enhanced primary production at the plume-oceanic interface of the Mississippi River; Cont. Shelf Res. 10 639-664.

Loisel H, Boss E, Stramski D, Oubelkheir K and Deschamps P-Y 2001 Seasonal variability of the backscattering coefficient in the Mediterranean Sea based on Satellite SeaWiFS imagery; Geophys. Res. Lett. 28 4203-4206.

McClain C R, Feldman G C and Hooker S B 2004 An overview of the SeaWiFS project and strategies for producing a climate research quality global ocean bio-optical time series; Deep-Sea Res. II 51 5-42.

Mishonov A V, Gardner W D and Richardson M J 2003 Remote sensing and surface POC concentration in the South Atlantic; Deep-Sea Res. II 50 2997-3015.

Mueller J L 1976 Ocean color spectra measured off the Oregon coast: Characteristic vectors; Appl. Opt. 15 394-402.

Neumann A, Krawczyk H and Walzel T 1995 A complex approach to quantitative interpretation of spectral high resolution imagery; In: Proc. Third Thematic Conf. Remote Sens. Mar. Coast. Environ. pp. II-641 \& II-652.

Ohlmann J C and Niiler P P 2005 Circulation over the continental shelf in the northern Gulf of Mexico; Prog. Oceanogr. 64 45-81.

Rabalais N N, Turner R E, Justic D, Dortch Q, Wiseman W J and Sen Gupta B K 1996 Nutrient changes in the Mississippi River and system responses on the adjacent continental shelf; Estuaries 19 386-407.

Redalje D G, Lohrenz S E and Fahnenstiel G L 1994 The relationship between primary production and the vertical export of particulate organic carbon matter in a riverimpacted coastal system; Estuaries 17 829-838.

Sathyendranath S, Prieur L and Morel A 1989 A threecomponent model of ocean colour and its application to remote sensing of phytoplankton pigments in coastal water; Int. J. Remote Sens. $101373-1394$.

Sharp J H 1974 Improved analysis for "particulate" organic carbon and nitrogen from seawater; Limnol. Oceanogr. $19984-989$

Son Y B 2006 POC algorithms based on spectral remote sensing data and its temporal and spatial variability in the Gulf of Mexico; Ph.D. Thesis, Texas A\&M University, USA.

Son Y B, Gardner W D, Mishonov A V and Richardson M J 2009 Multispectral remote sensing algorithms for particulate organic carbon (POC): The Gulf of Mexico; Remote Sens. Environ. 113 50-61. 
Stramska M and Stramski D 2005 Variability of particulate organic carbon concentration in the north polar Atlantic based on ocean color observation with Sea-viewing Wide Field-of-view Sensor (SeaWiFS); J. Geophys. Res. 110 C10018, doi:10.1029/2004JC002762.

Stramski D, Reynolds R A, Babin M, Kaczmarek S, Lewis M R, Röttgers R, Sciandra A, Stramska M, Twardowski M S and Claustre H 2008 Relationship between the surface concentration of particulate organic carbon and optical properties in the eastern South Pacific and eastern Atlantic Oceans; Biogeosciences 5 171-201.
Stramski D, Reynolds R A, Kahru M and Mitchell B G 1999 Estimation of particulate organic carbon in the ocean from satellite remote sensing; Science 285 239-242.

Twomey S 1977 Introduction to the Mathematics of Inversion in Remote Sensing and Indirect Measurements, (New York: Elsevier) p. 243.

Vastano A C, Barron Jr C N and Shaar E W 1995 Satellite observations of the Texas current; Cont. Shelf Res. 15 $729-754$.

Walker N D 1996 Satellite assessment of Mississippi River plume variability: Causes and predictability; Remote Sens. Environ. 58 21-35.

MS received 7 April 2008; revised 1 September 2008; accepted 20 September 2008 